\title{
The Influence of Mental Health on Labor Participation of Middle-aged and Elderly People in China: An Empirical Analysis Based on CHARLS Data
}

\author{
Yang $\mathrm{Yu}^{1, \mathrm{a},{ }^{*}, \mathrm{Li} \text { Zhang }}{ }^{2, \mathrm{~b},}$ and Linyue $\mathrm{Yu}^{3, \mathrm{c}}$ \\ ${ }^{1}$ School of Economics and Management Beijing Jiaotong University in Beijing, China \\ ${ }^{2}$ School of Economics and Management Beijing Jiaotong University in Beijing, China \\ ${ }^{3}$ School of Economics and Management Beijing Jiaotong University in Beijing, China \\ ayuyang_yh@163.com, bIzhang@bjtu.edu.cn, 'Iyyu@bjtu.edu.cn \\ *Corresponding author
}

Keywords: Mental health, Labor participation, Middle-aged and elderly people.

\begin{abstract}
In recent years, Chinese population life expectancy has continued to increase, but mental health problems have become increasingly prominent. In order to study the impact of mental health on labor participation, this paper uses the data of China Health and Retirement Longitudinal Study (CHARLS) in 2015 to empirically analyze the impact of mental health factors on the labor participation of middle-aged and elderly people in China over 45 years old. The results show that mental non-health tendency has a significant negative effect on the labor participation of middle-aged and elderly people in China. In the regression of gender heterogeneity, the negative impact of mental non-health tendency on men is more significant than that of women. In the regression of urban-rural heterogeneity, the group living in rural areas is more negatively affected by the mental non-health tendency.
\end{abstract}

\section{Introduction}

At present, the aging of population has become a very serious social problem in China, which has seriously affected the development of Chinese society and economy. According to the data released by the National Bureau of Statistics of China, in 2005-2016, the ratio of child rearing decreased year by year, and the elderly dependency ratio increased year by year. In addition, due to the reduction in the number of children in the family caused by the implementation of the family planning policy in China, and the transfer of rural labor in the process of urbanization, the number of Empty nest old man has been increasing[1]. These problems reflect the gradual disappearance of Chinese demographic dividends and the gradual reduction of labor resources. Therefore, improving the labor participation rate of middle-aged and elderly people is an important aspect to maintain economic development.

Health status is an important factor for individuals to decide whether to participate in labor, including mental health and physical health [2]. At present, the research on the impact of physical health on labor participation is very rich, but there is a lack of research on the impact of mental health on labor participation. Especially in the context of the growing life expectancy of our population and the increasingly prominent mental health problems, we can propose a strategic framework for improving mental health from the perspectives of individuals and families, so as to ensure the labor supply of middle-aged and elderly people, and thus ensure economic development.

\section{Literature review}

Currently, there are relatively few studies on the relationship between mental health and labor participation. Frijters, Paul, David Johnston and Michael Shields (2010) linked mental health to the labor market and found that a reduction in mental health could have a significant negative impact on participation in the labor market[3]. Lihua Zhu (2017) selected the depression index score (CES-D) in the mental health scale as a measure of mental health indicators, and used the probit model to 
empirically analyze whether rural middle-aged and elderly people participated in non-agricultural labor, and concluded that mental health can be significant. Non-agricultural labor participation affecting middle-aged and rural people in rural areas[4]. Jingjing Gao, Yishan Zhu and Xia Wang (2018) based on CHARLS panel data, gender heterogeneity analysis found that male labor participation is more negatively affected by depression tendency[5].

Most of the relevant literature, the indicators of mental health mainly include excessive abuse of mental illness, depression degree scale, smoking and alcohol abuse. Most of the research conclusions indicate that mental health has a significant negative impact on labor market behavior. And the research on the impact of mental health on labor participation in domestic literature is relatively scarce, and its impact mechanism remains to be explored. This paper attempts to use the data of CHARLS in 2015 to explore the impact of mental health on labor participation in middle-aged and elderly people in China.

\section{Data source and variable selection}

\subsection{Data source}

The CHARLS aims to collect high-quality data from families and individuals over 45 years old in China to analyze the ageing of the population and promote interdisciplinary research on ageing. The CHARLS national baseline survey was launched in 2011 and covers 150 county-level units, 450 village-level units, and approximately 10,000 households. This paper uses its 2015 survey data to conduct empirical research.

\subsection{Variable selection}

\subsubsection{Explained variable: labor participation}

Labor participation is mainly measured by a dummy variable, 0 means no participation in labor, 1 means participation in labor, including agricultural labor, employment work, etc.

\subsubsection{Explanatory variable: mental health status}

In this paper, the CES-D scale in CHARLS is used to measure whether the mental is healthy. A score of 0-10 indicates health mentality, while a score of 11-30 shows the tendency of unhealthy mentality. 3.2.3 Control variable

Control variables mainly include gender, age, education level, marital status, etc.

\section{Model and data descriptive statistics}

\subsection{Model}

Since the labor participation in this paper is a binary discrete variable, the binary selection model is selected for empirical analysis. The model form is as follows:

$$
\mathrm{Y}_{\mathrm{i}}=\alpha_{\mathrm{i}}+\beta \mathrm{MH}_{\mathrm{i}}+\delta \mathrm{X}_{\mathrm{i}}+\mu_{\mathrm{i}}
$$

In equation (1), $\mathrm{Y}_{\mathrm{i}}$ represents the virtual variable of individual labor participation, $\mathrm{MH}_{\mathrm{i}}$ represents the mental health status of the individual, and $\mathrm{X}_{\mathrm{i}}$ represents the control variable. The control variables selected in this paper are mainly gender, age and permanent residence.

\subsection{Data descriptive statistics}

Table 1 is a descriptive statistic of the sample population and its classification by sex and place of residence. The overall labor participation rate of the sample is close to $67 \%$, and the average age is about 58 years old. The proportion of mental non-health tendency is about 33.17\%. Male samples account for about $51 \%$ of the total, and rural samples account for about $68 \%$ of the total.

From the perspective of labor participation rate, male labor participation rate is about $68.9 \%$, higher than female labor participation rate of $61.2 \%$. The labor participation rate of rural groups is about $75.2 \%$, which is much higher than the urban group's $49.7 \%$. 
From the score of the psychological scale, the average score of the sample is 9.16. The score of men is lower than that of the women, and the score of urban population is lower than that of the rural population. The proportion of women with mental non-health tendency is about $40.7 \%$, which is higher than that of men. The proportion of people living in rural areas with mental non-health tendency is about 36\%, higher than those living in urban areas. (The numbers in parentheses in all tables in this article indicate the standard deviation.)

Table 1. Descriptive statistics of major variables

\begin{tabular}{cccccc}
\hline Variable & Total sample & $\begin{array}{c}\text { Male } \\
\text { sample }\end{array}$ & $\begin{array}{c}\text { Female } \\
\text { sample }\end{array}$ & $\begin{array}{c}\text { Urban } \\
\text { sample }\end{array}$ & $\begin{array}{c}\text { Rural } \\
\text { sample }\end{array}$ \\
\hline Proportion[\%] & 100 & 50.69 & 49.31 & 32.11 & 67.89 \\
\hline $\begin{array}{c}\text { Labor } \\
\text { participation } \\
\text { rate[\%] }\end{array}$ & 66.97 & 68.87 & 61.21 & 49.73 & 75.16 \\
\hline CES-D score & $(0.47)$ & $(0.45)$ & $(0.49)$ & $(0.50)$ & $(0.43)$ \\
\hline Mental & 9.16 & 8.18 & 10.16 & 8.52 & 9.46 \\
non-health[\%] & $(5.24)$ & $(4.81)$ & $(5.47)$ & $(4.59)$ & $(5.50)$ \\
\hline Age & $(0.43)$ & 25.83 & 40.72 & 27.16 & 36.02 \\
& 58.37 & $(0.44)$ & $(0.49)$ & $(0.44)$ & $(0.48)$ \\
\hline
\end{tabular}

Table 2 is the statistics of labor participation rate of groups with different mental health status according to gender and place of residence. Overall, the labor participation rate of mental health groups was $67.8 \%$, while the labor participation rate of mental non-health groups was $65.4 \%$. According to gender, the labor participation rate of men is still higher than that of women. According to the classification of residences, the labor participation rate of the population living in rural areas is higher than those living in urban areas. For women, mental health and mental non-health labor participation rates were $61.21 \%$ and $61.20 \%$, respectively, with little difference.

Table 2. Labor participation status

\begin{tabular}{|c|c|c|c|c|c|c|}
\hline & & $\begin{array}{c}\text { Total } \\
\text { sample }\end{array}$ & $\begin{array}{c}\text { Male } \\
\text { sample }\end{array}$ & $\begin{array}{l}\text { Female } \\
\text { sample }\end{array}$ & $\begin{array}{c}\text { Urban } \\
\text { sample }\end{array}$ & $\begin{array}{c}\text { Rural } \\
\text { sample }\end{array}$ \\
\hline \multirow{2}{*}{$\begin{array}{c}\text { Labor } \\
\text { participation } \\
\text { rate[\%] }\end{array}$} & $\begin{array}{c}\text { Mental } \\
\text { health }\end{array}$ & 67.83 & 72.98 & 61.21 & 50.71 & 77.05 \\
\hline & $\begin{array}{c}\text { Mental } \\
\text { non-health }\end{array}$ & 65.35 & 71.60 & 61.20 & 47.11 & 71.80 \\
\hline
\end{tabular}

\section{Empirical results and analysis}

In order to study the influence of mental non-health on the labor participation of middle-aged and elderly people in China, probit regression was performed on the model firstly. The regression results are shown in Table 3. Column 1 and 2 are respectively univariate regression used mental non-health tendency as the explanatory variable and regression with control variables added. Column 3 and column 4 are respectively univariate regression used CES-D scale score as the explanatory variable and regression with control variables added.

According to the regression results, mental non-health tendency has a significant negative impact on labor participation, and still remain the same after adding control variables. The psychological scale score also has a negative impact on labor participation, and the addition of control variables does not change this result. From the perspective of gender, there is a positive relationship between men and labor participation. However, the age and permanent residence of towns are negatively correlated with labor participation. 
Table 3. The influence of mental non-health tendency on labor participation

\begin{tabular}{|c|c|c|c|c|}
\hline & 1 & 2 & 3 & 4 \\
\hline Mental non-health & $\begin{array}{c}-0.694^{* * *} \\
(0.0268)\end{array}$ & $\begin{array}{c}-0.080 * * * \\
(0.0289)\end{array}$ & - & - \\
\hline CES-D score & - & - & $\begin{array}{c}-0.0064^{* * *} \\
(0.0024)\end{array}$ & $\begin{array}{c}-0.0056^{* * *} \\
(0.0026)\end{array}$ \\
\hline Male & - & $\begin{array}{c}0.435 * * * \\
(0.0277)\end{array}$ & - & $\begin{array}{c}0.436 * * * \\
(0.0279)\end{array}$ \\
\hline Age & - & $\begin{array}{c}-0.035^{* * *} \\
(0.0011)\end{array}$ & - & $\begin{array}{c}-0.035^{* * *} \\
(0.0011)\end{array}$ \\
\hline Urban & - & $\begin{array}{c}-0.762 * * * \\
(0.0285)\end{array}$ & - & $\begin{array}{c}-0.760 * * * \\
(0.0285)\end{array}$ \\
\hline Cons & $\begin{array}{c}0.463 * * * \\
(0.0155)\end{array}$ & $\begin{array}{c}2.579 * * * \\
(0.0686)\end{array}$ & $\begin{array}{c}0.499 * * * \\
(0.0255)\end{array}$ & $\begin{array}{c}2.603 * * * \\
(0.0725)\end{array}$ \\
\hline
\end{tabular}

Note: $* * *, * *$, and $*$ are respectively significant at $1 \%, 5 \%$ and $10 \%$ levels.

Based on the regression of the overall data, this paper further analyzes the heterogeneity of male and female samples. The results are shown in Table 4. Whether it is male or female, the existence of mental non-health tendency has a negative impact on labor participation, and has a greater negative impact on male labor participation. Age and residence in urban areas also have a significant negative impact on labor participation.

Table 4. Gender heterogeneity analysis

\begin{tabular}{ccc}
\hline & \multicolumn{2}{c}{ Labor participation } \\
\cline { 2 - 3 } & Male & Female \\
\hline \multirow{2}{*}{ Mental non-health } & $-0.1015^{* *}$ & $-0.0732^{*}$ \\
& $(0.0446)$ & $(0.0381)$ \\
\hline \multirow{2}{*}{ Age } & $-0.0442^{* * *}$ & $-0.0285^{* * *}$ \\
& $(0.0018)$ & $(0.0014)$ \\
\hline \multirow{2}{*}{ Urban } & $-0.7411^{* * *}$ & $-0.7903^{* * *}$ \\
& $(0.0416)$ & $(0.0394)$ \\
\hline \multirow{2}{*}{ Cons } & $3.6006^{* * *}$ & $2.2250^{* * *}$ \\
& $(0.1141)$ & $(0.0862)$ \\
\hline
\end{tabular}

Note: $* * *, * *$, and $*$ are respectively significant at $1 \%, 5 \%$ and $10 \%$ levels.

In order to understand the impact of different types of permanent residence on labor participation, this paper also analyzes the heterogeneity of urban and rural areas on the basis of full sample regression. The results are shown in Table 5. It can be seen that mental non-health tendency has a negative impact on both rural and urban samples, and has a greater impact on rural samples.

Table 5. Urban-rural heterogeneity analysis

\begin{tabular}{ccc}
\hline & \multicolumn{2}{c}{ Labor participation } \\
\cline { 2 - 3 } & Rural & Urban \\
\hline \multirow{2}{*}{ Mental non-health } & $-0.0944^{* * *}$ & -0.0740 \\
& $(0.0349)$ & $(0.0522)$ \\
\hline \multirow{2}{*}{ Male } & $0.3716^{* * *}$ & $0.5611^{* * *}$ \\
& $(0.0344)$ & $(0.0475)$ \\
\hline \multirow{2}{*}{ Age } & $-0.0280^{* * *}$ & $-0.0487 * * *$ \\
& $(0.0013)$ & $(0.002)$ \\
\hline \multirow{2}{*}{ Cons } & $2.2103^{* * *}$ & $2.5623^{* * *}$ \\
& $(0.0817)$ & $(0.1154)$
\end{tabular}

Note: $* * *, * *$, and $*$ are respectively significant at $1 \%, 5 \%$ and $10 \%$ levels. 


\section{Summary}

This paper uses the data of CHARLS in 2015 to study the impact of mental health status of middle-aged and elderly people over 45 years old on their labor participation. The results show that mental non-health tendency has a significant negative impact on labor participation. Moreover, from the perspective of gender differences, the mental non-health tendency has a greater negative effect on men than women. Seen from the regional differences, the negative effects of mental non-health on the samples whose permanent residence is rural areas are greater. In the total sample, about 33.2\% of individuals have mental non-health tendency, which indicates that mental non-health tendency has become an important factor affecting the labor participation of middle-aged and elderly people in China.

Under the circumstance that Chinese population is aging and the labor supply of middle-aged and elderly people is becoming more and more important, improving people's mental health can effectively improve the labor participation rate of middle-aged and elderly people, thus promoting economic development. Therefore, the government needs to pay attention to the mental health of middle-aged and elderly groups, and provide more support for medical insurance and social security for different characteristic groups.

\section{References}

[1] Tao Fang and Run Yi, The impact of the health status of urban retired young people on their own labor participation: Based on China Health and Pension Tracking Questionnaire Data. Southern magazine, vol. 2, pp. 43-56, 2015.

[2] Qin Li, Xiaoyan Lei and Yaohui Zhao, The impact of health on the labor supply of middle-aged and elderly people in China. Economics (Quarterly), vol. 13, pp. 917-938, 2015.

[3] Frijters, Paul, David Johnston and Michael Shields, Mental Health and Labour Market Participation: Evidence from IV Panel Data Models. IZA Discussion Paper, No. 4883.

[4] Lihua Zhu, The impact of mental health on labor participation and productivity: Taking middle-aged and elderly groups as the analysis object. Guangdong Social Sciences, vol. 2, pp. 37-44, 2017.

[5] Jingjing Gao, Yishan Zhu and Xia Wang, The influence of depression tendency on labor participation of middle-aged and elderly people in China: Empirical Analysis Based on CHARLS Panel Data. Labor economic research, vol. 1, pp. 63-80, 2018. 